\section{in the final analysis}

"Groups that are too much alike find it harder to keep learning, because each member is bringing less and less new information to the table. Homogeneous groups are great at doing what they do well, but they become progressively less able to investigate alternatives."

JOMI

Volume 67

Number 9

September 2015

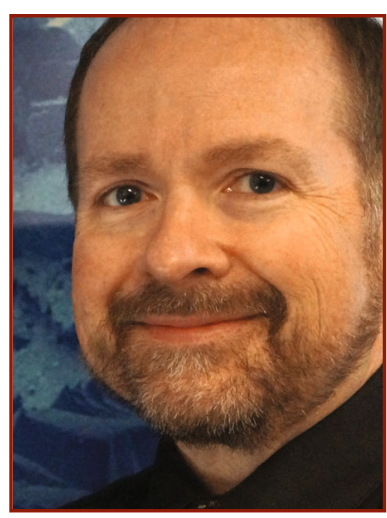

James J. Robinson Executive Director

Pragmatically speaking, I tend to find the prescriptions presented in management books more nostrum than cure-all. That's okay, as pretty much all of the well-known and even lesser-known books have some helpful takeaways or insights. Personally, I like some of what Surowiecki is advancing as it supports an idea that I find personally compelling: Better decisions tend to be made by groups of people with differing backgrounds, opinions, and experiences. While TMS is not consciously going the wisdom-of-crowds route, the society is absolutely striving for expanded diversity and inclusion at all levels of the society. As in 2014, 2015 sees much ongoing action with Goal 1 of the 2018 TMS Strategic Plan: "Advance diversity and inclusion in the minerals, metals, and materials profession." Honestly, TMS has been taking an all-season approach:

- In winter 2015, TMS released the toolkit and report from 2014's Diversity in the Minerals, Metals, and Materials Professions (DMMM1) conference. These are free for anyone in the community to download from the TMS website. The TMS Board of Directors also charged the Membership and Student Development Committee with overseeing the society's diversity efforts.

- In spring 2015, the TMS Women in Materials Science and Engineering Committee adopted a more inclusive focus by recasting itself as the TMS Diversity Committee.

- In summer 2015, the TMS Board of Directors approved conducting Diversity in the Minerals, Metals, and Materials Professions 2 (DMMM2). The second summit will focus on the underrepresentation of race and gender from the perspectives of government, academia, and industry. It will also emphasize the development and implementation of personnel skills and sharing of resources that participants can use upon returning to their workplaces. For purposes of networking and collegiality, the summit will be held on the campus of Northwestern University, July 25-27, 2016.

- In fall 2015, we continue our diversity spotlight in $J O M$, with this issue featuring Martha Goodway, who is well known for her pioneering work at the Smithsonian Institution.

As we move toward an increasingly heterogeneous world and decision-making environment, I'm reminded of yet another well-liked management book, Who Moved My Cheese? An Amazing Way to Deal with Change in Your Work and in Your Life by Spencer Johnson. In parable fashion, he looks at life and change using the metaphors of mice and cheese. Is my thesis that TMS is like cheese? Nah, but I will observe that there are more than 900 types of cheese in the world. I suspect that there's room for every variety at our table.
"Pragmatically speaking, I tend to find the prescriptions presented in management books more nostrum than cure-all." 